\title{
A APRENDIZAGEM DO AUTISTA (TEA) E A INTERVENÇÃO NEUROPSICOPEDAGÓGICA
}

\section{ARTIGO ORIGINAL}

GONÇALVES, Alzira de Sousa Paiva ${ }^{1}$

GONÇALVES, Alzira de Sousa Paiva. A aprendizagem do autista (TEA) e a intervenção neuropsicopedagógica. Revista Científica Multidisciplinar Núcleo do Conhecimento. Ano 05, Ed. 06, Vol. 06, pp. 32-40. Junho de 2020. ISSN: 2448-0959, Link de acesso: https://www.nucleodoconhecimento.com.br/educacao/aprendizagemdo-autista

\section{RESUMO}

Este artigo propõe uma reflexão sobre a aprendizagem de alunos autistas (TEA) em rede regular de ensino e a intervenção Neuropsicopedagógica. Mais especificamente, busca entender como as adaptações curriculares e a contribuição da Neuropsicopedagogia podem favorecer a aquisição de novos conhecimentos e de novas habilidades do aluno com TEA, por entender que a Neuropsicopedagogia é uma grande aliada a aprendizagem de alunos especiais, por reunir conhecimentos da neurociência, psicologia e pedagogia. Com isso, traçar estratégias de ensino, através de tratamentos terapêuticos e auxílio ao professor no ensino regular. Para isso, o Neuropsicopedagogo busca realizar uma avaliação personalizada de como o cérebro da criança aprende, viabilizando um aprendizado eficiente. Este estudo torna-se relevante por proporcionar mais pesquisas nesta área de estudo. Este trabalho foi realizado através de pesquisa bibliográfica de artigos científicos de periódicos na área

${ }^{1}$ Pós-Graduação a nível de especialização em Neuropsicopedagogia Clínica. Pós Graduação a Nível de Especialização em Língua Inglesa e Formação de Professores. Graduação em Pedagogia. 
de estudos, consulta de livros sobre o autismo e sites de Saúde, Google Acadêmico e o banco de dados da Scientific Eletronic Library Online - SciELO.

Palavras-Chave: Autismo, aprendizagem, neuropsicopedagogia.

\section{INTRODUÇÃO}

Atualmente, com o crescente número de crianças especiais matriculadas no ensino regular, cresce a preocupação com a aprendizagem desses alunos e como podem ser feita intervenções e adaptações no currículo para que possam atender a essa diversidade de crianças e alcançar a tão sonhada e real inclusão em sala de aula. Contudo, muitos desafios são encontrados no ensino para que haja um avanço no aprendizado dessas crianças, especialmente, alunos autistas, que é o foco deste estudo.

A aprendizagem de alunos autistas é cercada por muitos desafios para pais, professores e profissionais envolvidos neste processo, por entender que precisam ser traçadas estratégias personalizadas para cada criança, de acordo com a sua realidade e vivência, a fim de valorizar o seu potencial e viabilizar a aquisição de novos conhecimentos, integração social e desenvolvimento de novas habilidades. Para potencializar esse aprendizado de forma especializada, que a Neuropsicopedagogia busca contribuir através de intervenções no processo de aprendizagem de forma terapêutica, com o intuito de melhorar os aspectos cognitivos, linguísticos e social da criança com necessidades especiais (MENEZES, 2019).

Baseado nisso, questiona-se: Como a Neuropsicopedagogia pode contribuir para o progresso do aluno com autismo (TEA)? É possível realizar adaptações curriculares no ensino regular para incluir e auxiliar o aprendizado de alunos com TEA?

A Neuropsicopedagogia favorece a aprendizagem de alunos com TEA, pois busca entender como o cérebro da criança aprende e processa as informações oferecidas, contribuindo para proporcionar programas de ensino que estimulem a criança a adquirir novos conhecimentos e prevenir que os sintomas do autismo sejam 
confundido com síndromes, outros transtornos e demais anomalias, fornecendo uma atuação eficiente. Com isso, auxiliar professores, pais e mediadores para a realização de adaptações curriculares e monitoramento dessa aprendizagem. É possível realizar adaptações curriculares que favoreçam a aprendizagem de crianças autistas no ensino regular. No entanto, o professor precisa ser assessorado e conhecer a forma como seu aluno aprende.

O objetivo deste trabalho é refletir sobre a aprendizagem do aluno autista e como a Neuropsicopedagogia pode contribuir nesse processo. Mais especificamente, entender como as intervenções psicopedagógicas e as adaptações curriculares podem favorecer a aquisição de novas habilidades desses alunos.

Este estudo torna-se relevante por proporcionar mais pesquisas que contribuam para o conhecimento sobre a aprendizagem de alunos com TEA e a importância das intervenções neuro psicopedagógicas, a fim de melhorar o entendimento nessa área. A motivação para esta pesquisa foi a de entender o que pode ser feito para auxiliar professores e pais para o ensino de crianças autistas em virtude do crescente número de crianças especiais matriculadas na rede de ensino regular.

Este trabalho foi realizado através de pesquisa bibliográfica de artigos científicos de periódicos na área de estudos, consulta de livros sobre o autismo e sites de Saúde, Google Acadêmico e o banco de dados da Scientific Eletronic Library Online - SciELO.

\section{DESENVOLVIMENTO}

O Autismo, segundo o dicionário online de língua portuguesa[2], vem a ser um Transtorno Global do Desenvolvimento (TGD), caracterizado por alterações no desenvolvimento neurológico, pela dificuldade de socialização, de comunicação verbal ou uso da linguagem. O Autismo, também conhecido como Transtorno do Espectro Autista (TEA), encontra-se contido na Classificação Internacional de Doenças (CID 10 - F84), pela Organização Mundial de Saúde (OMS), por tratar-se de um tema de saúde mental, que apresenta alterações cerebrais na pessoa que a possui, podendo afetar também a aprendizagem. Com isso, esse transtorno pode 
ocorrer tanto isoladamente, como também associado a outros transtornos ou comorbidade.

As características do TEA podem ser apresentadas na criança com o transtorno desde muito cedo, já em seus primeiros anos de vida, sendo também mais comum em meninos, que em meninas. O comprometimento do Transtorno do Espectro Autista pode ter classificação de leve a severa, sendo o diagnóstico essencialmente clínico, a partir de relatos e observações dos pais ao médico (NASCIMENTO; CRUZ e BRAUN, 2017).

A aprendizagem do aluno com TEA é cercada por muitos desafios, tanto para as crianças e pais, quanto para os professores, pois para que o aluno possa atingir o seu potencial e desenvolver-se em sua maneira mais plena possível, a escola precisa reformular sua estrutura e planejar novas formas de ensinar, a fim de que haja de fato a inclusão da criança com autismo.

Segundo Vasconcelos (2019):

As lutas pela aprendizagem são várias e contínuas, deixando marcas tantas vezes irreparáveis. Uma das principais marcas poderá situar-se na autoestima: a vergonha apodera-se delas ao verificarem que o que é tão simples para os colegas não é para elas. E mesmo aquelas tarefas que parecem triviais do dia-a-dia, transformam-se em pesadelos constantes, inibidoras das qualidades que, porventura, elas possam possuir.

Diante dos desafios encontrados na escolarização de crianças especiais, a escola deve, constantemente, traçar estratégias pedagógicas e de inclusão, a fim de trabalhar a diversidade em sala de aula, valorizar os avanços de cada criança e de potencializar a autoestima, além de favorecer o desenvolvimento da aprendizagem. No entanto, muitas vezes, esses desafios só são possíveis de serem vencidos através do apoio de uma equipe multidisciplinar, transdisciplinar, auxílio médico, terapêutico e com mediação em sala de aula. 
Algumas crianças que precisam de auxílio diferenciado, como no caso daquelas ditas autistas ou psicóticas, passam a ser acompanhadas por um mediador no contexto escolar. Esse acompanhamento geralmente também é orientado por profissionais que assistem a esse aluno fora da escola, como psicólogos, terapeutas ocupacionais, médicos, entre outros (VARGAS e RODRIGUES, 2018).

Conhecer as características individuais de cada criança autista torna-se o primeiro passo para traçar estratégias de aprendizagem e avaliação deste aluno, pois é a partir das necessidades pessoais, da sua realidade e vivência, que é possível proporcionar novas oportunidades de experiência e novos conhecimentos. Um exemplo disso foi um trabalho realizado por uma professora de Fundamental I, atuando com um aluno com TEA, na qual buscou conhecer as habilidades e dificuldades desse aluno, para então viabilizar o conhecimento de novas capacidades:

A partir dessa visão de uma educação baseada em procedimentos especiais, Julia (Professora) descreveu como organizava a preparação de cada um dos assuntos trabalhados para Paulo (aluno autista). Ela contou que desenvolveu atividades seguindo uma mesma estrutura tanto para as atividades e avaliações em sala, quanto para os trabalhos e tarefas para a casa. Ela utilizou a mesma instrução alterando as alternativas, figuras ou palavras. Tais estratégias ofereceram uma base para o aluno, uma vez que ele sabia exatamente o que a professora esperava dele com aquela atividade. $O$ modo de apresentar a instrução da atividade mostrou-se fundamental, pois certos modos tornavam a atividade mais difícil para o aluno analisar o que era esperado dele. A nova forma de organizar o conjunto de atividades favoreceu uma ansiedade menor do aluno, de modo que ele conseguisse se expressar e responder melhor àquilo que era solicitado (APORTA e LACERDA, 2018).

A aprendizagem de alunos especiais requer flexibilidade e adaptações curriculares constante, com o intuito de proporcionar acessibilidade a aquisição de novos 
conhecimentos, integração social e desenvolvimento de novas habilidades. Contudo, a eficácia dessa aprendizagem requer intervenções de uma equipe que dê continuidade a esse trabalho realizado em sala de aula, por profissionais que assessorem esse processo, como é o caso do Neuropsicopedagogo.

A Neuropsicopedagogia busca contribuir para potencializar as habilidades cognitivas, emocionais e sociais, possibilitando o melhor desenvolvimento das intervenções dos aspectos cognitivos, linguístico e social da criança com necessidades especiais (MENEZES et al, 2019). Além disso, o Neuropsicopedagogo realiza planejamentos que assessoram o processo de aprendizagem da criança autista, estimulando as funções a partir das habilidades já adquiridas, realizando intervenções, orientação e terapias cognitivas para melhorar o processo de aquisição da aprendizagem.

A Neuropsicopedagogia surge como sendo uma ciência transdisciplinar que reúne conhecimentos das áreas da neurociência cognitiva, a pedagogia e a psicologia. A neurociência ligada à educação em termos gerais, é o estudo de como o cérebro aprende. É o entendimento de como as redes neurais são submetidas no momento da aprendizagem, bem como de que maneira os estímulos chegam ao cérebro, de forma como as memórias se consolidam e de como temos acesso a essas informações armazenadas. Os alicerces dessa prática neuro psicopedagógica são as teorias e as estratégias de ensinoaprendizagem. As metodologias utilizadas nessa prática terão que levar em consideração vários pontos como o estímulo perceptivo desde os primeiros anos de vida até os sete anos de idade, como forma de prevenção de sintomas que possam ser confundidos com síndromes, transtornos e demais anomalias, auxiliando assim a formatação e programação correta das redes neurais da criança. Visa também o estímulo perceptivo e intelecto emocional de crianças e adolescentes com dificuldades cognitivas visando a redução de sintomas com base na plasticidade cerebral (VASCONCELOS, 2019). 
Baseado nisso, para um desenvolvimento pleno da aprendizagem, o autista necessita de uma intervenção estruturada, com organização do espaço, material, atividades e rotinas de trabalhos bem elaborados, amparados de apoio visual realizado por um profissional Neuropsicopedagogo (MENEZES et al, 2019). Esse profissional alia os conhecimentos da neurociência, da pedagogia e psicologia proporcionando estratégias terapêuticas que estimulem as funções cerebrais e promova a alfabetização, o desenvolvimento da linguagem, a interação social e estimule as funções de coordenação motora, importantes para o desenvolvimento da aprendizagem. Porém, as estratégias terapêuticas são traçadas pelo neuropsicopedagogo somente após uma avaliação clínica das potencialidades da criança.

Segundo Menezes et al, (2019):

A Neuropsicopedagogia clinica faz uso de instrumentos especificamente padronizados para a avaliação das funções do cérebro, habilidades no processamento das atenções, informações, memória, percepção, abstração, linguagem, raciocínio, aprendizagem, habilidades acadêmicas, processamento de informações, viso construção, afeto, funções motoras e executivas atuando no diagnostico, no tratamento, na pesquisa da cognição, das emoções, da personalidade e do comportamento para melhor entender o funcionamento do cérebro.

As avaliações são importantes para o conhecimento de como o cérebro da criança processa as informações e lida com elas. Com isso, traçar estratégias que desenvolvam novas funções no cérebro, pela sua plasticidade, através de tratamentos terapêuticos. Contudo, para o profissional ter certeza de que realmente a criança está progredindo em seu desenvolvimento e se pode continuar com a estratégia traçada, gerando novos desafios ou reformulá-la para novas adaptações, avaliações precisam ser refeitas periodicamente.

Umas das ferramentas terapêuticas utilizadas pelos Psicopedagogos e Neuropsicopedagogos, elaborado especialmente, para alunos autistas é o programa 
TEACCH (Treatment and Education of Autistic and Related Communication Handicapped Children), que é um programa transdisciplinar de tratamento e educação para crianças autistas, criado em 1964, na Universidade do Norte da California. Ela tem como base o contexto da criança para que ela possa construir uma visão do mundo e de si mais coerente possibilitando o seu desenvolvimento e ajudando a diminuir a ansiedade (SANTOS, 2005). Além disso, esse programa de ensino utiliza como recursos para a aprendizagem padrões visuais em suas atividades e jogos.

Outro meio terapêutico que auxilia na aprendizagem do autista é o método $A B A$ (Applied Behavior Analysis). A terapia ABA, criada em 1968 por uma abordagem da psicologia, tem tido grandes resultados, pois "recorre-se" à observação e à avaliação do comportamento do indivíduo, no sentido de potencializar a sua aprendizagem e promover o seu desenvolvimento e autonomia (NETO et al, 2013)

Cada vez mais tem se intensificado os estudos aliados a neurociência, a psicologia e a educação, com o intuito de alcançar maneiras eficazes de impulsionar o aprendizado. Com isso, o trabalho neuropsicopedagógico propõe a criação de estratégias e utilização de recursos visuais, tecnológicos, musicoterápicos, ou outros que se adequem ao perfil da criança, a fim de potencializar as habilidades, proporcionar novas aprendizagens e maximizar as chances de aprendizagem da criança especial.

\section{CONCLUSÃO}

Este estudo buscou entender como é a aprendizagem de alunos Autistas e como a Neuropsicopedagogia pode contribuir para viabilizar a aprendizagem de novos conhecimentos e novas habilidades desses alunos. A aprendizagem de crianças com TEA ainda é um desafio para muitos, pois requer o conhecimento personalizado de como o cérebro de cada aluno aprende, quais são as suas capacidades e limitações. Com isso, traçar estratégias terapêuticas e curriculares que favoreçam o aprendizado, além de contribuir para a diminuição da ansiedade, buscando adaptações curriculares a partir de sua vivência e das habilidades já adquiridas. 
A aprendizagem de alunos especiais requer flexibilidade e adaptações curriculares por parte dos professores. É possível realizar adaptações personalizadas que contribuam para a inclusão e o conhecimento destes alunos, com atividades visuais e estratégicas, que ajudem o aluno a compreender o que é esperado dele. A Neuropsicopedagogia é uma grande aliada na aprendizagem destes alunos por se tratar de uma ciência transdisciplinar, contribuindo para o seu progresso. Após uma avaliação Neuropsicopedagógica, é possível obter dados do aluno com TEA e realizar um planejamento de atividades e métodos que favoreçam o conhecimento destes alunos. Com isso, auxiliar professores, pais e mediadores para a realização de adaptações curriculares e monitoramento dessa aprendizagem.

\section{REFERÊNCIAS}

APORTA, Ana Paula; LACERDA, Cristina Broglia Feitosa de. Estudo de Caso sobre Atividades Desenvolvidas para um Aluno com Autismo no Ensino Fundamental I. Rev. bras. educ. espec. vol.24, n.1 Bauru Jan./Mar. 2018. Disponível em: $<$ http://www.scielo.br/scielo.php?script=sci_arttext\&pid=S141365382018000100045\&lang=pt>. Acesso em: 05 mar. 2020.

DÍCIO-DICIONÁRIO ONLINE DE PORTUGUÊS. Disponível em: <https://www.dicio.com.br/autismo/>. Acesso em: 05 mar. 2010.

MENEZES, Maria Carolina Cavalcanti de Almeida; et al. Intervenções neuropsicopedagógicas em casos de autismo. VI Congresso Nacional de Educação, 2019.

em: <https://www.editorarealize.com.br/revistas/conedu/trabalhos/TRABALHO_EV1 27_MD4_SA10_ID783_22092019121035.pdf>. Acesso em: 05 mar. 2020.

NASCIMENTO, Fabiana Ferreira do; CRUZ, Mara Monteiro da; BRAUN, Patrícia. Escolarização de pessoas com transtorno do espectro do autismo a partir da análise da produção científica disponível na Scielo-Brasil (2005-2015). Arquivos Analíticos de Políticas Educativas, Vol. 25, n. 125. 2017. Disponível em: $<$ https://www.redalyc.org/pdf/2750/275043450111.pdf>. Acesso em: 20 fev. 2020. 
NETO, Otílio Paulo da S.; et al, G-TEA: Uma ferramenta no auxílio da aprendizagem de crianças com Transtorno do Espectro Autista, baseada na metodologia ABA. SBC - Proceedings of SBGames 2013. Disponível em: $<$ http://www.sbgames.org/sbgames2013/proceedings/cultura/Culture-18_full_GTEA.pdf>. Acesso em: 06 mar. 2020.

PORTALPEBMED. CID 10 - Classificação Internacional de Doenças. Disponível em: $<$ https://pebmed.com.br/cid10/transtornos-globais-do-desenvolvimento/>. Acesso em: 05 mar. 2010.

SANTOS, Françoise Debelle dos. Autismo e psicologia clínica de abordagem dinâmica numa sala TEACCH: reflexões e partilha duma prática. Revista Portuguesa de Psicossomática. Vol. 7, n. 1-2. 2005. Disponível em: $<$ https://www.redalyc.org/pdf/287/28770216.pdf>. Acesso em: 06 mar. 2020.

VARGAS, Thamyres Bandoli Tavares; RODRIGUES, Maria Goretti Andrade. Mediação escolar: sobre habitar o entre. Revista Brasileira de Educação. vol.23, 2018. Disponível em: <http://www.scielo.br/scielo.php?script=sci_arttext\&pid=S141324782018000100270\&lang=pt\#B22>. Acesso em: 05 mar. 2020.

VASCONCELOS, Erivalda Cavalcante Mendes de. 2019. Inclusão de crianças com Transtorno Global do Desenvolvimento (TGD) na escola regular. Disponível em: $<$ https://www.fjn.edu.br/repositorioinstitucional/wp-content/uploads/2020/01/ArtigoErivalda-Cavalcante-Mendes-de-Vasconcelos.pdf>. Acesso em: 05 mar. 2020.

\section{APÊNDICE - REFERÊNCIA DE NOTA DE RODAPÉ}

2. Disponível em:<https://www.dicio.com.br/autismo/> Dício-Dicionário online de Português.

Enviado: Abril, 2020.

Aprovado: Junho, 2020. 